\title{
Wear Evaluation Following Clinical use of Retrieved Polyethylene Mobile Inserts in Rotaglide Total Knee Replacement with a Combined Qualitative and Quantitative Topographic Method
}

\author{
Anastasios P Nikolaides ${ }^{1 *}$, Fares Sayegh ${ }^{2}$, Athanasios Tsakonas ${ }^{3}$ and Apostolos J Polyzoides \\ ${ }^{1}$ Senior Orthopaedic and Trauma Specialist, University of Birmingham, UK
}

${ }^{2}$ Professor in Trauma and Orthopaedics, Aristotle University of Thessaloniki, Greece

${ }^{3}$ Retired Consultant Orthopaedics and Trauma Surgeon, Hippokratio General Hospital, Greece

${ }^{4}$ Retired Consultant Orthopaedics and Trauma Surgeon, Solihull Hospital, UK

Submission: September 18, 2018; Published: October 12, 2018

*Corresponding author: Anastasios P Nikolaides, Senior Orthopaedic and Trauma Specialist, Honorary Senior Lecturer University of Birmingham, Heart of England NHS Foundation Trust, Heartlands Hospital, Bordesley Green East, B9 5SS, Birmingham, UK, Tel: 00447931939605;

Email: a.nikolaidis@bham.ac.uk

\begin{abstract}
Background: The Rotaglide Total Knee System was introduced into clinical practice in 1988. It was the first condylar Total Knee Endoprosthesis with a highly conforming mobile polyethylene insert which rotates and glides on top of a highly polished tibial component, thus theoretically reducing wear.

Materials and Methods: We studied the wear of 17 retrieved Rotaglide mobile polyethylene inserts bearings. In all cases The Posterior Cruciate Ligament was preserved. The mean time of in vivo use was 8 years ( 3 months to 15.6 years). To measure the PE, wear we used a new method of evaluation, by calculating the percentage of contact surface with signs of specific mode of wear.

Results: Thinner inserts showed moderate to severe wear after 9.5 years. In $51-85 \%$ of the total upper surface delamination dominates, but plastic deformation and pitting to a much extend are also present. Little wear of burnishing type and abrasions develop after 5.5 years mainly in the posterior condyles and in the thin inserts is accompanied by fracture and loss of material. In all bearings, there is no significant backside wear. $18 \%$ of the backside surface had no wear, $42 \%$ showed some abrasions and scattered areas of burnishing and the remaining $40 \%$ is dominated by pitting inside areas of burnishing.
\end{abstract}

Conclusion: Delamination predominantly, combined with polyethylene fracture of the thinner inserts is the main wear pattern of the upper articular surface. In all inserts, there was no significant backside wear.

Keywords: Rotaglide Total Knee Arthroplasty; Polyethylene wear; Mobile insert

\section{Introduction}

Polyethylene wear remains one of the major contributors of failure in Total Knee Arthroplasty [1,2]. It affects either the upper articulating with the femoral component surface of the insert, or the backside surface articulating with the tibial component. Although upper surface wear is predominant [3-5], backside wear has also been responsible for accumulation of wear debris in the synovial fluid [6,7]. Polyethylene wear particles in turn trigger an inflammatory granulomatous response with accumulation of macrophages and the release by them of cytokines. The result is osteolysis and aseptic loosening of the implants [8,9]. Recent studies have not shown any difference in the concentration of wear particles in the synovial fluid in fixed or mobile inserts [10]. However fixed bearing is linked to increased backside wear when the articulating upper surface is more conforming, compared to flatter contact surface [11].

The Rotaglide Total Knee Arthroplasty was introduced into clinical practice in 1988. It was the first Total knee implant which used a mobile polyethylene fully conforming insert which glided and slide on top of a highly polished tibial component Although there are several reports in the literature regarding long term clinical results of this prosthesis [12-19], to our knowledge there are no studies describing wear patterns of its fully conforming mobile PE insert. Evaluation of wear on the retrieved Polyethylene inserts in knee prostheses has generated a great amount of work since the beginning of the eighties, because these observations have led to a better understanding of the wear mechanisms. A 
general review of the literature regarding the methods used for wear evaluation shows that most of the studies are based upon a system of gradation as described by Hood in 1983 [20]. They define 7 different modes of wear, a 4-point severity scale, and 10 different zones to obtain a total score reflecting the total wear and the different modes involved.

This method has been improved to include an estimation of the surface of worn areas, expressed in area (mm2) or as a percentage of the articulating surface [21]. More recently, enhancement of resolution of commercial cameras and use of commercial software has led to an easier work [22]. Backside wear of fixed inserts has also been evaluated, mainly by similar methods [23] with adaptation due to the necessity of evaluating gross deformation in the screw holes of the tibial tray, or by methods involving coordinate measurement machines (CMM) [24], since unworn backside surfaces are generally plan. CMM methods have not been extensively used [25] for evaluating wear of articulating surfaces of retrieved implants, because they need knowledge of the unworn surface of a similar or even better the same implant. CMM methods are powerful when used to evaluate wear on implants tested in knee wear simulators, as demonstrated by Muratoglu [26] who used in conjunction a gravimetric method to demonstrate how true wear can be separated from creep in the CMM results. For the purposes of this project, a review of the scientific literature has been made to collect typical photographs of the different types of wear, according to the definitions used by Hood [20] and adopted by many other authors.

\section{Materials and Methods}

Seventeen retrieved tibial inserts of Rotaglide total knee prostheses were collected, sterilized and submitted for wear evaluation. The implantation time varies from 2 years to 15.6 years (mean $=8.7$ years, standard deviation $=4.5$ years). In all cases the Posterior Cruciate Ligament was preserved (Table 1). For all the inserts except one, the anatomical side (left or right) of implantation is unknown and cannot be deduced from the reference code, as the Rotaglide PE insert is totally symmetrical to be indifferently implanted on a left or on a right knee. Four (4) inserts were retrieved because of early sepsis (from 2 years to 5 years) and were totally unworn. From the remaining 13 inserts, 12 were broken: 10 were broken in 2 parts ( 9 with breakage of one of the two bearing surfaces, 1 with breakage in the middle), the other 2 were broken in 3 parts (breakage of the two bearing surfaces). Unfortunately, from theses 12 broken inserts, only 6 were complete, the other 6 presented at least one missing part that had not been delivered to the lab.

Table 1: Retrieved polyethylene tibial inserts (Rotaglide), sorted by increasing $\mathrm{N}^{\circ}$.

\begin{tabular}{|c|c|c|c|c|c|c|c|}
\hline № & $\begin{array}{c}\text { Time of } \\
\text { Implantation } \\
\text { (Years) }\end{array}$ & Thickness(mm) & Side & $\begin{array}{l}\text { Marking generally } \\
\text { 2markings: } 1 \text { of each side } \\
\text { can be incomplete }\end{array}$ & $\begin{array}{l}\text { Reason } \\
\text { Explant }\end{array}$ & $\begin{array}{l}\text { Number of } \\
\text { parts }\end{array}$ & Comments \\
\hline 1 & 2 & 14,5 & $?$ & $\begin{array}{c}\text { 102204c023298 size1 } 14.5 \mathrm{~mm} \\
\text { PE }\end{array}$ & sepsis & 1 & Unworn \\
\hline 2 & 3.1 & 12 & $?$ & $\begin{array}{c}\text { 102.203c05359 size } 112 \mathrm{~mm} \\
\text { PE }\end{array}$ & sepsis & 1 & Unworn \\
\hline 3 & 5 & 9,5 & $?$ & (laser) 102.202 size1 PE 7391 & sepsis & 1 & Unworn \\
\hline 4 & 9.8 & 9,5 & $?$ & 1270170 & & 2 & $\begin{array}{l}\text { break (Missing } \\
1 \text { piece) }\end{array}$ \\
\hline 5 & 5.5 & 9,5 & $?$ & 127200245 & & 2 & break ( 2 pieces) \\
\hline 6 & 15.4 & 7 & $?$ & 1272013339 & & 2 & $\begin{array}{l}\text { totally worn } \\
\text { upside } \& \text { break } \\
(2 \text { pieces })\end{array}$ \\
\hline 7 & 10.6 & 7 & $?$ & 12720201 & & 3 & $\begin{array}{l}\text { break (missing } \\
2 \text { pieces) }\end{array}$ \\
\hline 8 & 13.6 & 17 & $?$ & 127205333978 & & 1 & \\
\hline 9 & 11.5 & 7 & $?$ & 12720085 & & 2 & break ( 2 pieces) \\
\hline 10 & 15.6 & 7 & $?$ & 1270 (break) 0 & & 2 & $\begin{array}{c}\text { totally worn+ } \\
\text { break \& missing } \\
1 \text { piece }\end{array}$ \\
\hline 11 & 12 & 7 & $?$ & 2010378 & & 2 & $\begin{array}{l}\text { break (missing } \\
1 \text { piece) }\end{array}$ \\
\hline 12 & 3.8 & 9,5 & $?$ & $\begin{array}{c}\text { 102202c009506 size } 19.5 \mathrm{~mm} \\
\text { PE }\end{array}$ & sepsis & 1 & unworn \\
\hline 13 & 7.8 & 9,5 & $?$ & 12720085 & & 2 & $\begin{array}{l}\text { break (missing } \\
1 \text { piece) }\end{array}$ \\
\hline 14 & 10 & 9,5 & $?$ & 127245 & & 3 & $\begin{array}{l}\text { break (missing } \\
2 \text { pieces) }\end{array}$ \\
\hline
\end{tabular}




\begin{tabular}{|c|c|c|c|c|c|c|c|}
\hline 15 & 9.6 & 7 & $?$ & 1270458 & 2 & break (2 pieces) \\
\hline 16 & 11 & 9,5 & $?$ & 27202333978 & & $\begin{array}{c}\text { break (2 } \\
\text { pieces). Female }\end{array}$ \\
\hline 17 & 2 & 7 & right & (laser) (c) 127 201 PE1422 & $\begin{array}{c}\text { not worn but } \\
\text { break 2 pieces; } \\
\text { male; valgus }\end{array}$ \\
\hline
\end{tabular}

For each insert, capture of the images of the frontside and backside was made by a digital camera (Nikon Coolpix 5400, 5 Megapixels). The digital zoom was avoided in order not to compromise resolution. Flash light was avoided as it reflects too much on the polyethylene surface. However, digital cameras have generally no problem with ambient light. A ruler was positioned in the same focal plane as the wear surface, to be used as calibration reference for the computation of absolute wear areas if needed.

\section{Results}

Overview: The observation of the 17 implants revealed that they can be classified in four different groups, according to Table 2: Classification of the retrieved PE tibial inserts. their general aspect and macroscopic degree of wear:

Group A: The implants are macroscopically not worn and are not broken. They correspond to the implants that were retrieved for sepsis.

Group B: The implants have low wear, and they have at least one broken condyle.

Group C: The implants have moderate wear, and they have at least one broken condyle.

Group D: The implants are totally worn. In this case they can be unbroken or have at least one broken part.

\begin{tabular}{|c|c|c|c|c|c|c|}
\hline \multicolumn{7}{|c|}{ Classification of the retrieved PE tibial inserts } \\
\hline Group & № & $\begin{array}{c}\text { Time in Service } \\
\text { (Yrs) }\end{array}$ & Thickness (mm) & Broken Condyle & $\begin{array}{c}\text { Mean Time in } \\
\text { Service (yrs) }\end{array}$ & $\begin{array}{c}\text { Mean Thickness } \\
(\mathrm{mm})\end{array}$ \\
\hline $\begin{array}{c}\text { A } \\
\begin{array}{l}\text { No wear \& Not } \\
\text { broken }\end{array}\end{array}$ & $\begin{array}{c}1 \\
2 \\
12 \\
13\end{array}$ & $\begin{array}{l}2.0 \\
3.1 \\
3.8 \\
5.0\end{array}$ & $\begin{array}{c}14.50 \\
12.00 \\
9.50 \\
9.50\end{array}$ & & 3.48 & 11.38 \\
\hline $\begin{array}{c}\text { B } \\
\text { Low wear \& } \\
\text { broken condyle (s) }\end{array}$ & $\begin{array}{c}17 \\
5 \\
13 \\
15\end{array}$ & $\begin{array}{l}2.0 \\
5.5 \\
7.8 \\
9.6\end{array}$ & $\begin{array}{l}7.00 \\
9.50 \\
9.50 \\
7.00\end{array}$ & $\begin{array}{l}1 \\
1 \\
1 \\
1\end{array}$ & 6.23 & 8.25 \\
\hline $\begin{array}{c}\text { C } \\
\text { Moderate wear \& } \\
\text { broken condyle (s) }\end{array}$ & $\begin{array}{c}4 \\
14 \\
7 \\
9 \\
11\end{array}$ & $\begin{array}{c}9.8 \\
10.0 \\
10.6 \\
11.5 \\
12.0\end{array}$ & $\begin{array}{l}9.50 \\
9.50 \\
7.00 \\
7.00 \\
7.00\end{array}$ & $\begin{array}{c}1+ \\
2 \\
2 \\
1 \\
1\end{array}$ & 10.78 & 8 \\
\hline $\begin{array}{c}\text { D } \\
\text { Totally worn }\end{array}$ & $\begin{array}{c}6 \\
8 \\
16 \\
10\end{array}$ & $\begin{array}{l}15.4 \\
13.6 \\
11.0 \\
15.6\end{array}$ & $\begin{array}{c}7.00 \\
17.00 \\
9.50 \\
7.00\end{array}$ & $\begin{array}{l}\text { middle } \\
\qquad \begin{array}{c}1+ \\
1+\end{array}\end{array}$ & 13.9 & 10.13 \\
\hline
\end{tabular}

This very simple classification according to the general aspect is very easy to operate, and the four isolated groups are rather consistent. Table 2 presents the available data of individual implants, when they are grouped according to the above classification. "Thickness" refers to the nominal thickness of the implanted PE inserts, and corresponds to the one given in the manufacturer's catalogue. This information was provided by the surgeons who retrieved the implants. In the column 
"broken condyle", "1" indicates that only one condyle is broken, and the other is intact; and " $1+$ " indicates one broken condyle and the other in bad condition. "Middle" indicates that the insert is broken in two parts, along an anteroposterior line, passing through the plane of symmetry of the insert. Inside each group, the appearance of PE inserts is rather consistent, and the difference between the four groups is evident. This can be appreciated by studying 4 of the inserts one related to a specific group (Figures 1-4).
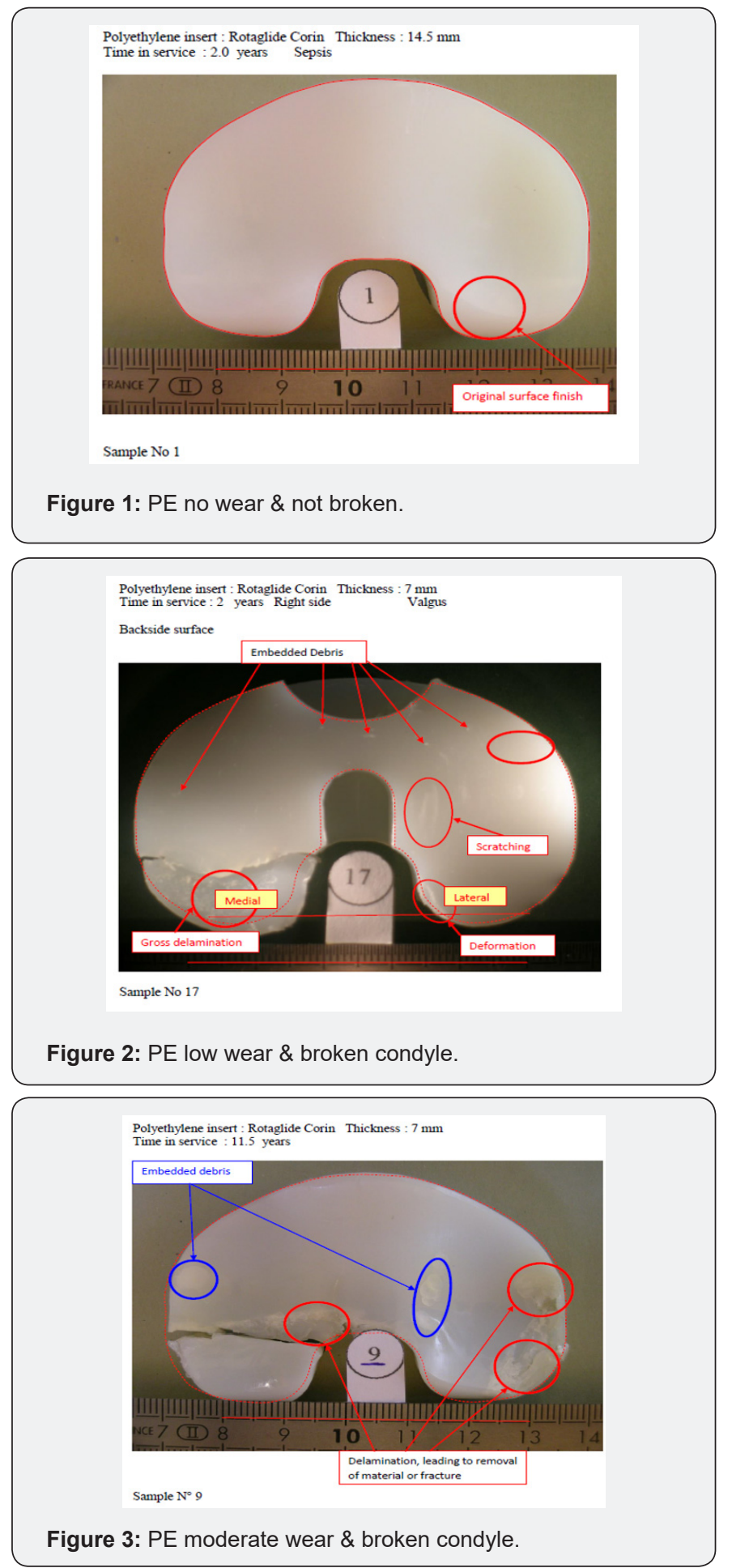

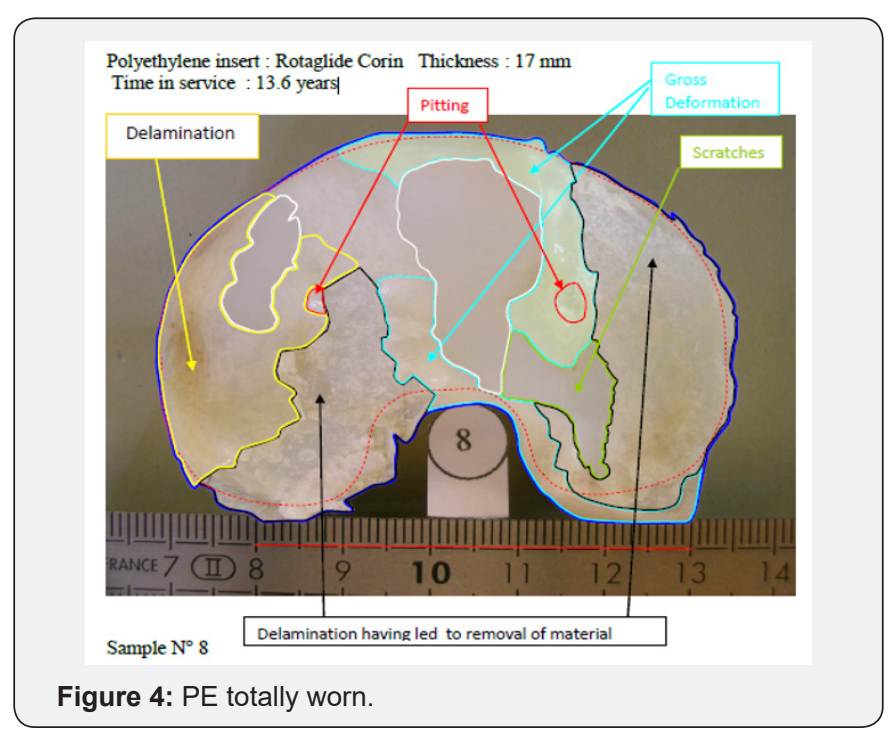

The results of this classification reveal the following: In group A, are gathered 4 inserts retrieved for early sepsis, and of different thickness, from 9.5 to $14.5 \mathrm{~mm}$. This is supposed to give an indication about the normal distribution between the implanted inserts, as the sepsis is not related to a specific characteristic of the implant. The time in service varies from 2 years to 5 years (mean 3.48 years). The traces of wear are very slight, and very difficult to photograph because of light reflection on the polyethylene.

Group B gathers 4 inserts that have low wear but have a broken condyle. Except the case of sample $\mathrm{n}{ }^{\circ} 17$ which has prematurely failed after 2 years, (valgus, broken lateral condyle), the time in service varies from 5.5 years to 9.6 years (mean 6.23 years). In this group, only inserts of $7 \mathrm{~mm}$ and $9.5 \mathrm{~mm}$ thickness are present. This may suggest that such thin inserts are overstressed in the bearing surfaces, above the fatigue limit of the polyethylene. Group $C$ gathers 5 inserts that are more worn that group B, because they have survived more under the stresses that tend to break the condyles. The time in service varies from 9.8 to 12 years (mean 10.78 years). Just like group B, only inserts of $7 \mathrm{~mm}$ and $9.5 \mathrm{~mm}$ thickness are represented. In two occasions, the inserts have the two condyles broken. The appearance of the inserts reveals also gross deformation or delamination of the posterior aspect of the surviving condyles.

Group D gathers 4 inserts that exhibit severe wear, mainly delamination that leads to the fracture of the upper surface and material removal. The time in service varies from 11.0 to 15.6 years (mean 13.90 years). Two of the inserts have a broken condyle and the other is in bad condition, one exhibiting a longitudinal fracture after wear of the anterior aspect. These 3 broken inserts have thickness of 7 to $9.5 \mathrm{~mm}$. The only insert which is unbroken has a thickness of $17 \mathrm{~mm}$, which seems to prevent from overstressed leading to fractures.

From these results and assuming the examined PE inserts are representative of the population of retrieved Rotaglide inserts, it may be deduced that the main reasons for retrieval before 10 
years in service, is either early sepsis, or fracture of at least one condyle. In this case, and even with up to 10 years in service, the wear remains moderate. The fracture of the condyle(s) mainly happens with thin PE inserts, $7 \mathrm{~mm}$ or $9.5 \mathrm{~mm}$ thick. Such thin inserts can occasionally survive until 15 years without fracture of the condyles but exhibit severe wear. The same type of wear can also be seen on thicker inserts; these latter ones having the advantage of being apparently prevented from condyle fractures due to the thickness of polyethylene in this sensible zone.

\section{Definitions on Characterization of Wear}

The qualitative characterization of wear lies upon the definitions of Hood [20] and Cornwall [21]. Seven different types of wear have been described and documented by these authors: $\mathrm{s}$

a. Delamination is a subsurface laminate mechanism of degradation characterized by a visual opacity as the crack (or craze) propagates through the material beneath and approximately parallel to the surface. Delamination is a fatigue-related phenomenon.

b. Pitting is characterized by small defects observed on the articular surface. Pitting is also thought to be a fatiguerelated phenomenon; however, it has not been established whether the pit initiation is a surface or subsurface mechanism.

c. Abrasion is characterized by a tufted appearance usually caused by high friction articulation as the polymer bearing surface comes into direct contact with bone or bone cement. Macroscopically, abraded areas appear significantly rougher than the original machined polymer surface. Microscopically, tearing of the polymer is clear.

d. Scratching usually occurs in the direction of articulation and is often associated with third body wear or surface irregularities. Microscopically, scratching is a combination of deformation and removal of material.

e. Burnishing is a micro polishing mechanism causing the bearing surface to appear smoother than the original surface. It is not known whether this process is associated with the removal of fine particulate debris or a surface heating effect leading to viscous flow.

f. Deformation involves the permanent depression of the polymeric bearing material without material removal.

g. Embedded debris is usually identified as bone and bone cement fragments on the polymeric bearing surface. Metallic beads from porous coating removal and debris from metal-on-metal contact are third bodies that adversely affect the articulation.

h. An additional mechanism, Failure, is included to describe areas of completely removed bearing surface leading to contact between the femoral condyle and the metal backing of either the tibial plateau or the patellar component.

\section{Qualitative Evaluation}

In the group $\mathrm{A}$, the bearing surfaces appear very lightly worn. Some scratches are visible, as well as burnishing, which is defined as the removal of the original surface finish. This kind of wear can also be seen at the backside, the burnishing / scratching areas appearing at the periphery, and rather on the posterior aspect. Note that the original surface finish of the backside and upper surface are different: backside shows marks of machining while upper surface does not.

\section{For Group A}

PE no wear \& not broken. Burnishing areas of the backside cannot be seen on the actual photographs, because of the reflection of the light on the polyethylene. Contours of sample $\mathrm{n}{ }^{\circ} 1$ have been depicted and copied to the other samples, after adjustment to the correct scale and eventual rotation. It generally fits rather well, showing that this system could be imported to more worn implants, to superpose the shape of the presumed original implant.

\section{For Group B}

PE low wear \& broken condyle. Sample 17 which presents a broken condyle after 2 years in service shows that the fractures initiates from the backside, after a gross delamination of the posterior side of the lateral condyle. The other 3 inserts do not show such gross delamination, but plastic deformation at the backside near the fracture. The front side reveals only slight scratching oriented according to the movement of the femoral part against the polyethylene bearing surface.

\section{For Group C}

PE moderate wear \& broken condyle. The initiation of the fracture of the condyles is mainly located on the front side, after gross delamination of the surface. The traces of wear are much more visible than in the previous group. Zones of delamination, plastic deformation, larges scratches can be seen. In sample $n{ }^{\circ} 9$, embedded debris can be suspected.

\section{For Group D}

PE totally worn. All types of wear are represented and cover almost the totality of the implant surface. Gross delamination is predominant, with removal of large parts of the surface. Plastic deformation is also present on large areas; the polyethylene is mainly pushed to the periphery. Sample ${ }^{\circ} 8$ has been extensively characterized and can be examined for the different types of wear, by opening the PE totally worn.doc. Note that this insert, $17 \mathrm{~mm}$ thick and extensively worn on the frontside, presents a backside in good condition except the posterior edge of the two condyles. On the contrary, the three other inserts of this group exhibit large zones of delamination and plastic deformation on their backside.

The four groups exhibit different degrees of wear, showing the evolution of degradation according the time in service. It seems that fracture of the condyles is a phenomenon not directly related to wear, as in group B fractures occurred 
without extensive wear. On the contrary, it seems to be related to overstressed, probably due to the thickness of the polyethylene in the bearing zone.

\section{Quantitative Evaluation}

These results concern the evaluation of worn areas for two groups:

Group A (inserts macroscopically not worn on the front side and not broken, corresponding to retrieval for early sepsis) for the backside because these inserts exhibit typical patterns that can be easily depicted with low magnification. As the backside of the implants is flat, the photographs generally show significant light reflection, and cannot be directly exploited.

The different characteristic types of surfaces are the following ones:

1: the surface is intact, without scratches and the marks of original machining are present.

2: the marks of original machining are still visible, but the surface exhibits also some scratches.

$2+$ : this is the evolution of the previous one, with attenuated marks of machining and more visible scratches.

$2++$ : marks of machining very attenuated and deep and numerous scratches.

Table 3: Quantitative analysis of backside wear in Group A inserts.
3: the surface is burnished, very well polished, without trace of machining, and without or very attenuated scratches.

We can consider that the abrasive phenomenon concerns mainly the transformation of type 1 areas into type 2 , and then type $2+$ and $2++$. On the contrary, as noted by Cornwall, the topology of type 3 areas rather suggests a cold flow deformation. The delimitation of the different types of areas was handmade through a fine felt-tip marker, directly on the PE insert. Pictures of these inserts were then captured (Nikon Coolpix 5.1 Megapixels) and treated with 2 specifics.

Software Packages: Adobe Photoshop for colouring the different areas according to the type of wear, and Image J for measuring in $\mathrm{mm}^{2}$ the various worn surface areas. For each insert, the surface areas corresponding to the different types of wear have been computed and expressed as a percentage of the total surface. The results are summarised in Table 3, Different regions corresponding to the previous definitions have been coloured from light grey for type 1, to dark grey for type 2++, and pink for type 3 . The characteristic shape of the burnished regions can be noted, which appears at the periphery of the inserts; for types 2, 2+ and 2++ the patterns of the scratches cannot be represented, but their orientation suggests a rotation of the insert relatively to the peg of the tibial tray.

\begin{tabular}{|c|c|c|c|c|c|}
\hline \multicolumn{6}{|c|}{ Backsides polyethylene inserts Rotaglide Group A: Retrieved for early sepsis } \\
\hline & $\begin{array}{c}n^{\circ} 1 \\
2.0 \mathrm{yrs}\end{array}$ & $\begin{array}{c}\mathrm{n}^{\circ} 2 \\
3.1 \mathrm{yrs}\end{array}$ & $\begin{array}{c}\mathrm{n}^{\circ} 12 \\
3.8 \mathrm{yrs}\end{array}$ & $\begin{array}{c}\mathrm{n}^{\circ} 3 \\
5.0 \mathrm{yrs}\end{array}$ & Mean \\
\hline Type & Surface & Surface & Surface & Surface & Surface \\
\hline of wear & $\%$ & $\%$ & $\%$ & $\%$ & $\%$ \\
\hline 1 & $37,14 \%$ & & $33,81 \%$ & & $17,74 \%$ \\
\hline 2 & $32,05 \%$ & $52,52 \%$ & $18,47 \%$ & $7,88 \%$ & $27,73 \%$ \\
\hline $2+$ & & & $19,69 \%$ & $23,11 \%$ & $10,70 \%$ \\
\hline $2++$ & & & $3,72 \%$ & $9,47 \%$ & $3,30 \%$ \\
\hline all 2 & & & $41,89 \%$ & $40,46 \%$ & $41,73 \%$ \\
\hline 3 & $30,81 \%$ & $47,48 \%$ & $24,30 \%$ & $55,04 \%$ & $39,41 \%$ \\
\hline Pitting & & & & $4,50 \%$ & $1,12 \%$ \\
\hline
\end{tabular}




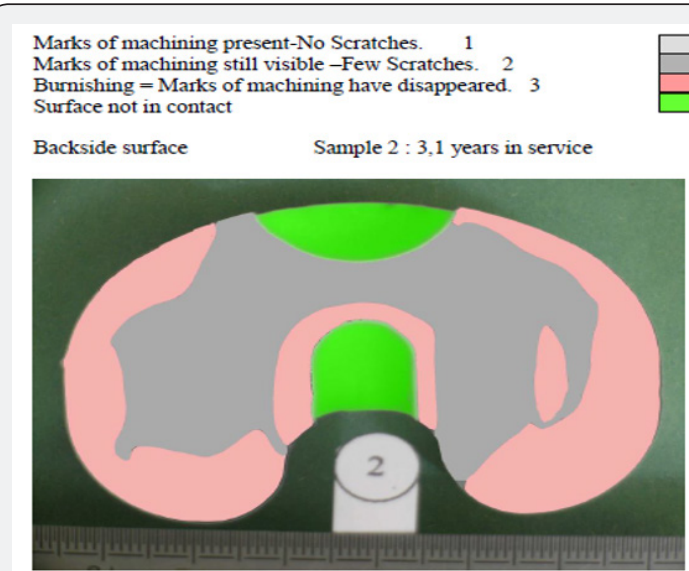

Figure 5: Marks of Machining have disappeared.

In samples $\mathrm{n}{ }^{\circ} 2$ (3.1 years in service) Figure 5 and $\mathrm{n}{ }^{\circ} 3$ (5 years in service) Figure 6, surfaces of type 1 (marks of machining visible, no scratches) have disappeared to the profit of surfaces of type 2 (marks of machining disappearing, scratches). Type 3 surfaces (burnished: marks of machining not visible, no scratches) are also more extended. On the oldest insert ( ${ }^{\circ} 3,5$ years in service) pitting appears in a region that was previously burnished. Group D (insert totally worn) for the upper surface in contact with the femoral elements. In this case, the different types of wear can be depicted directly on the original pictures. These pictures were treated with Adobe Photoshop for colouring the different areas with the different types of wear, and Image J for calculating the surface areas.

Table 4: Quantitative analysis of upper surface of Group D inserts.

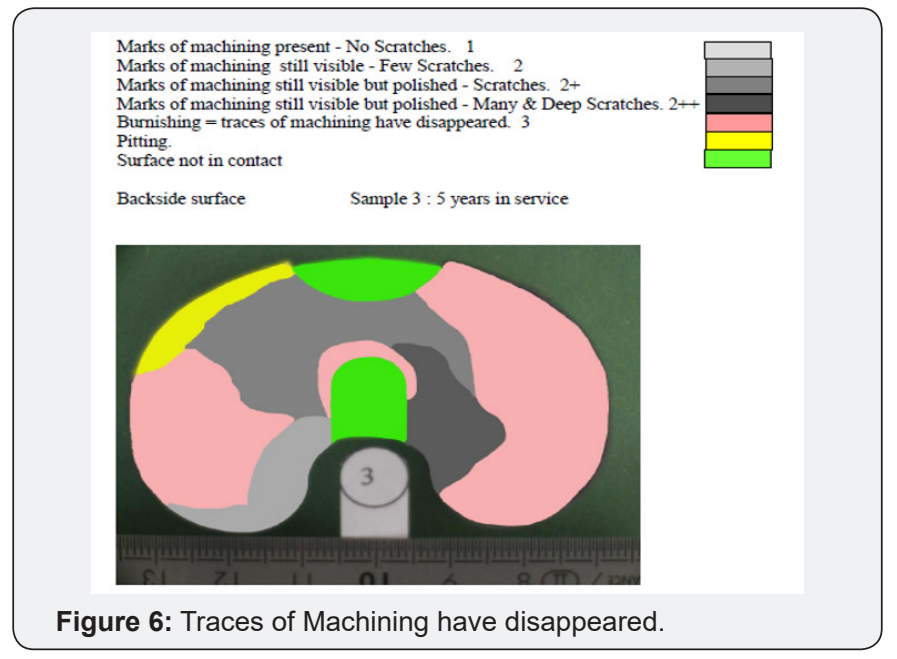

The definitions of the different types of wear used, are the ones presented the previous reports and corresponding to the common definitions given by the literature: delamination, pitting, abrasion, scratching, burnishing, deformation, embedded debris and failure. Additionally, delamination has been divided in 2 sub-groups: slight delamination, which means that the phenomenon is visible but has not removed material, and gross delamination with removal of material from the surface. The results can be seen in Table 4. Different regions corresponding to the previous definitions have been coloured. For each insert, the surface areas corresponding to the different types of wear have been computed and expressed as a percentage of the total available surface.

\begin{tabular}{|c|c|c|c|c|c|}
\hline \multicolumn{6}{|c|}{ Front sides Polyethylene inserts Rotaglide Group D: totally worn } \\
\hline & $\begin{array}{c}n^{\circ} 6 \\
15.4 \text { yrs }\end{array}$ & $\begin{array}{c}n^{\circ} 8 \\
13.6 \text { yrs }\end{array}$ & $\begin{array}{c}n^{\circ} 16 \\
11.0 \text { yrs }\end{array}$ & $\begin{array}{c}n^{\circ} 10 \\
15.6 \text { yrs }\end{array}$ & $\begin{array}{c}\text { Mean } \\
13.9 \text { yrs }\end{array}$ \\
\hline Type of Wear & Area $\%$ & Area $\%$ & Area \% & Area $\%$ & Area \% \\
\hline Gross delamination & $61,63 \%$ & $39,18 \%$ & $40,35 \%$ & $50,59 \%$ & $47,94 \%$ \\
\hline Slight delamination & $24,62 \%$ & $21,00 \%$ & $26,58 \%$ & & $18,05 \%$ \\
\hline Plastic deformation & & $16,16 \%$ & $10,42 \%$ & $9,71 \%$ & $9,07 \%$ \\
\hline Scratches & & $4,85 \%$ & & & $1,21 \%$ \\
\hline Pitting & & $0,53 \%$ & & & $0,13 \%$ \\
\hline Undetermined & $13,14 \%$ & $17,77 \%$ & $21,63 \%$ & $39,13 \%$ & $22,92 \%$ \\
\hline
\end{tabular}

In sample No 16 Figure 7 delamination is predominant; either without removal of material or with, this latter case being mostly associated to fracture. Plastic deformation, scratching and pitting are also present to a lesser extent, especially in the region that covers the slot dedicated to the metallic peg, where the polyethylene is thin; and, at the posterior edge of the bearing surfaces. 


\section{Orthopedics and Rheumatology Open Access Journal (OROAJ)}

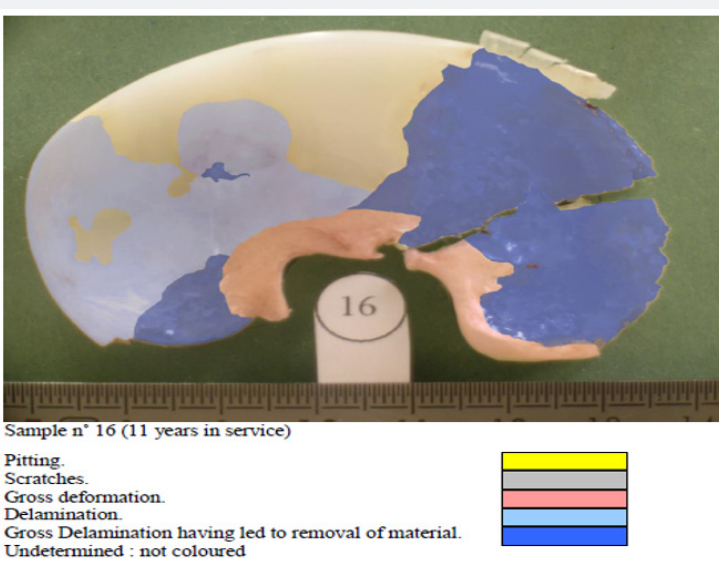

Figure 7: Gross Delamination having led to removal of material.

\section{Discussion}

Polyethylene wear and the subsequent osteolysis and loosening of Knee Arthroplasty implants remains an important cause of failure [27]. The extent of contact surface between components and Polyethylene affects the degree of wear $[28,29]$. The high contact surface of the Rotaglide Knee prosthesis as measured by Heim et al. [30] is the result of the high conformity of femoral component - PE insert interface. The combination of high conformity and the mobility of the insert reduces the Anteroposterior sliding of the femoral condyles on the insert thus reducing wear. The mobile insert also enhances a more physiological movement of the knee since it can rotate and slide on a highly polished metallic surface of the tibial component $[31,32]$. The result is a better kinematic environment and less constrain of the tibial component - bone interface [33]. The analysis of the wear of the retrieved inserts confirm this partially. In our study another important parameter is evident and involves the sterilisation of the inserts. Those who were produced before 1995 were sterilised in air, a process which can decrease their mechanical strength.

In our study such inserts showed the worst wear. It is also remarkable the presence of slight or no backside wear depending on the longevity of the inserts, a finding that is present in other publications regarding mobile inserts [34]. In 18\% of total backside surface there was no wear, in $42 \%$ scratching with burnishing and in the remaining 20\% pitting with burnishing was noted. Moderate and severe wear of the upper articular surface is noted in inserts with more than 9.5 years of function and thickness of $7 \mathrm{~mm}$ and $9.5 \mathrm{~mm}$. Delamination is the main wear pattern of these inserts and affects $66 \%$ of the total contact surface. Plastic deformation affects $9 \%$ and $1.5 \%$ shows pitting and scratching. The remaining surface cannot be assessed due to the fracture of the insert at the posterior condylar area and the loss of material.

Mild scratching and burnishing wear are evident after 5.5 years. Such wear mode is like other retrieved mobile inserts reported in previous studies [35-38] where PCL was also preserved and different from other studies where PCL was sacrificed [35]. It should also be mentioned that the alignment of scratches was rotational rather than longitudinal confirming the in vivo rotational ability of the mobile insert to the upper polished surface of the tibial component.

\section{Conclusion}

The analysis of 17 retrieved mobile polyethylene inserts in Rotaglide Total Replacement with a mean in vivo function of 8 years ( 3 months to 15.6 years) demonstrates that delamination is the main mode of wear affecting the upper articular surface. Thin inserts with 7.5 and $9 \mathrm{~mm}$ thickness were particularly vulnerable. In these inserts wear is accompanied by fracture of one or both posterior condyles and the loss of material. In all inserts regardless of thickness, there was no significant backside wear, which is mainly of burnishing and pitting type. Compliance with ethical standards.

\section{References}

1. Sharkey PF, Hozack WJ, Rothman RH, Shastri S, Jacoby SM (2002) Install Award Paper: why are total knee arthroplasties failing today? Clin Orthop Relat Res. 2002; 404: 7-13.

2. Atkins GJ, Haynes DR, Howie DW (2012) Role of polyethylene particles in periprosthetic osteolysis: a review. World J Orthop 2(10): 93.

3. Engh GA, Lounici S, Rao AR, Collier MB (2001) In vivo deterioration of tibial baseplate locking mechanisms in contemporary modular total knee components. J Bone Joint Surg Am 83(11): 1660-1665.

4. Holt G, Murnaghan C, Reilly J, Meek RM (2007) The biology of aseptic osteolysis. Clin Orthop Relat Res 460:240-252.

5. Naudie DD, Ammeen DJ, Engh GA, Rorabeck CH (2007) Wear and osteolysis around total knee arthroplasty. J Am Acad Orthop Surg 15: 53-64.

6. Collier MB, Engh CA, McAuley JP, Ginn SD, Engh GA (2005) Osteolysis after total knee arthroplasty: influence of tibial baseplate surface finish and sterilization of polyethylene insert. J BoneJoint Surg Am 87: 27022708.

7. Li S, Scuderi G, Furman BD, Bhattacharyya S, Schmieg JJ (2002) Assessment of backside wear from the analysis of 55 retrieved tibial inserts. Clin Orthop Relat Res 404: 75-82.

8. DeHeer DH, Engels JA, DeVries AS, Knapp RH, Beebe JD (2001) In situ complement activation by polyethylene wear debris. J Biomed Mater Res 54: 12-19.

9. Kadoya Y, Revell PA, Kobayashi A, al-Saffar N, Scott G, et al. (1997) Wear particulate species and bone loss in failed total joint arthroplasties. Clin Orthop Relat Res 340: 118-129.

10. Comparison of in vivo polyethylene wear particles between mobile and fxedbearing TKA in the same patients: Yukihide Minoda $1 \cdot$ Kanako Hata1 - Mitsuhiko Ikebuchi1 - Shigekazu Mizokawa1 Yoichi Ohta1 - Hiroaki Nakamur Knee Surg Sports Traumatol Arthrosc (2017) 25:2887-2893.

11. Ran Schwarzkopf MD,Richard D, Scott MD, Evan M, Carlson, et al (2015) Does Increased Topside Conformity in Modular Total Knee Arthroplasty Lead to Increased Backside Wear? Currier MSc Clin Orthop Relat Res 473: 220-225.

12. Polyzoides AJ, Dendrinos G, Tsakonas A (1996) The Rotaglide Total Knee Arthroplasty. Prosthesis design and early results. J Arthroplasty 11(4): 453-459. 
13. Stergios R, Ploumis, Avraam L, Chantzidis, Paraskevas T (2011) Rotaglide total knee arthroplasty: a long-term follow-up study Metsovitis. The Journal of Bone and Joint Surgery 93(9): 878-884.

14. Wilson CJ, Fitzgerald B, Tait GR (2003) Five-year review of the Rotaglide total knee Arthroplasty the Knee 10(2): 167-171.

15. Michael, Iliopoulos, Efthymios, Neofytou, Dimos et al. (2014) The Rotaglide mobile-bearing total knee arthroplasty: no difference between cemented and hybrid implantation Iosifidis. Anastasios Knee Surgery, Sports Traumatology, Arthroscopy 22(8): 1843-1848.

16. McGonagle, Lorcan, Bethell, Louisa, Byrne, et al. (2012) The Rotaglide total knee replacement: a comparison of mobile versus fixed bearings Ben Knee Surgery, Sports Traumatology, Arthroscopy.

17. Hudd Alastair, Kunasingam, Kumar Ricketts, David Bush (2009) A 5 to 8-year follow-up study of the Rotaglide mobile bearing total knee arthroplasty John International Orthopaedics 33(3): 675-678.

18. Horwitz M, Awan S, Chatoo M, Stott D, Powles D (2009) An 8- to 10year review of the Rotaglide total knee replacement International Orthopaedics 33(1): 111-115.

19. Simon J, Baird Karene, Young David, Tait Gavin R (2012) The Rotaglide mobile bearing knee arthroplasty: A 10- to 13-year review from an independent centre Spencer. The Knee p. 20-23.

20. Hood (1983) Retrieval analysis of total knee prostheses: A method and its application to 48 total condylar prostheses. J. Biomed Mater Res 17: 829-842.

21. Cornwall (1995) A quantitative technique for reporting surface degradation patterns of UHMWPE components of retrieved total knee replacements. J Appl Biomater. Spring 6(1): 9-18.

22. Grochowsky (2006) Digital photogrammetry for quantitative wear analysis of retrieved TKA components. J Biomed Mater Res, Applied Biomaterials pp. 263-267.

23. Cuckler (2003) Polyethylene damage on the nonarticular surface of modular total knee prostheses. CORR 410: 248-253.

24. Conditt (2005) Backside wear of polyethylene tibial inserts: mechanism and magnitude of material loss. J Bone Joint Surg 87A: 326-331.

25. Harman (2001) Polyethylene damage and knee kinematics after total knee arthroplasty. CORR 392: 383-393.

26. Muratoglu (2003) Metrology to quantify wear and creep of Polyethylene tibial knee inserts. CORR 410: 155-164
27. Rand JA, Trousdale RT, Ilstrup DM, Harmsen WS (2003) Factors affecting the durability of Primary Total Knee Prostheses. J Bone Joint Surg (Am) 85(2): 259-265

28. Argenson JN, O'Connor JJ (1992) Polyethylene wear in Meniscal knee replacement. J Bone Joint Surg (Br) 74: 228-232.

29. Plante-Bordeneuve P, Freeman MAR (1993) Tibial high-density polyethylene wear in conforming tibiofemoral prostheses. J Bone Joint Surg (Br) 75: 630-636.

30. Heim SC, Postak PD (1996) Tibial-Femoral Surfaces of the Corin Rotaglide Total Knee System. Report from the Depatment of Orthopaedic Research Laboratories Mount Sinai Medical Center Cleveland Annual Feb 2: 234-239

31. Callaghan JJ (2001) Mobile-bearing knee replacement: clinical results: a review of the literature. Clin Orthoepy 392: 221-225.

32. Delport HP, Banks SA, De Schepper J, Bellemans J (2006) A kinematic comparison of fixed- and mobile-bearing knee replacements. J Bone Joint Surg 88(8):1016-1021.

33. Morra EA, Postak PD, Plaxton NA (2003) Greenwald S: The effects of external torque on polyethylene tibial insert damage patterns. Clin Orthop 410: 90-100.

34. Kop AM, Swarts E (2007) Quantification of polyethylene degradation in mobile bearing knees: a retrieval analysis of the Anterior-PosteriorGlide (APG) and Rotating Platform (RP) Low Contact Stress (LCS) knee. Acta Orthop Scand 78(3): 364-370.

35. Fang-Yuan Ho, Hon-Ming Ma, Jiann-Jong Liau, Chuan-Ren Yeh (2007) Chun-Hsiung Huang: Mobile-bearing Knees Reduce Rotational Asymmetric Wear Clin Orthop 462: 143-149.

36. Collier JP, Mayor MB, McNamara JL, Surprenant VA, Jensen RE (1991) Analysis of the failure of 122 polyethylene inserts from uncemented tibial knee component Clin Orthop 273: 232-242.

37. Hirakawa K, Bauer TW, Yamaguchi M, Stulberg BN, Wilde AH (1999) Relationship between wear debris particles and polyethylene surface damage in primary total knee arthroplasty. J Arthroplasty 14: 165-171.

38. Wasielewski RC, Galante JO, Leighty RM, Natarajan RN, Rosenberg AG (1994) Wear patterns on retrieved polyethylene tibial inserts and their relationship to technical considerations during total knee arthroplasty. Clin Orthop 299: 31-43.
Your next submission with Juniper Publishers will reach you the below assets

- Quality Editorial service

- Swift Peer Review

- Reprints availability

- E-prints Service

- Manuscript Podcast for convenient understanding

- Global attainment for your research

- Manuscript accessibility in different formats

( Pdf, E-pub, Full Text, Audio)

- Unceasing customer service

Track the below URL for one-step submission https://juniperpublishers.com/online-submission.php 